\title{
Target screening of plant secondary metabolites in river waters by liquid chromatography coupled to high-resolution mass spectrometry (LC-HRMS)
}

\author{
Mulatu Yohannes Nanusha ${ }^{1,2}$, Martin Krauss ${ }^{1}$, Carina D. Schönsee ${ }^{3,4}$, Barbara F. Günthardt ${ }^{3}$, Thomas D. Bucheli ${ }^{3}$ \\ and Werner Brack ${ }^{1,2^{*}}$
}

\begin{abstract}
Background: Substantial efforts have been made to monitor potentially hazardous anthropogenic contaminants in surface waters while for plant secondary metabolites (PSMs) almost no data on occurrence in the water cycle are available. These metabolites enter river waters through various pathways such as leaching, surface run-off and rain sewers or input of litter from vegetation and might add to the biological activity of the chemical mixture. To reduce this data gap, we conducted a LC-HRMS target screening in river waters from two different catchments for 150 plant metabolites which were selected from a larger database considering their expected abundance in the vegetation, their potential mobility, persistence and toxicity in the water cycle and commercial availability of standards.

Results: The screening revealed the presence of 12 out of 150 possibly toxic PSMs including coumarins (bergapten, scopoletin, fraxidin, esculetin and psoralen), a flavonoid (formononetin) and alkaloids (lycorine and narciclasine). The compounds narciclasine and lycorine were detected at concentrations up to $3 \mu \mathrm{g} / \mathrm{L}$ while esculetin and fraxidin occurred at concentrations above $1 \mu \mathrm{g} / \mathrm{L}$. Nine compounds occurred at concentrations above $0.1 \mu \mathrm{g} / \mathrm{L}$, the Threshold for Toxicological Concern (TTC) for non-genotoxic and non-endocrine disrupting chemicals in drinking water.

Conclusions: Our study provides an overview of potentially biologically active PSMs in surface waters and recommends their consideration in monitoring and risk assessment of water resources. This is currently hampered by a lack of effect data including toxicity to aquatic organisms, endocrine disruption and genotoxicity and demands for involvement of these compounds in biotesting.
\end{abstract}

Keywords: Natural toxins, Bioactive compounds, Mixture toxicity, Surface water, Emerging contaminants

\section{Background}

Plants produce a large variety of chemical compounds, which may be categorized as primary and secondary metabolites. Primary metabolites are necessary for growth and maintenance of cellular functions of the

\footnotetext{
*Correspondence: werner.brack@ufz.de

${ }^{1}$ Department of Effect-Directed Analysis, Helmholtz Centre for Environmental Research-UFZ, Permoserstraße 15, 04318 Leipzig, Germany

Full list of author information is available at the end of the article
}

plant while secondary metabolites play an important role, for example as defence (against herbivores, microbes, viruses or competing plants) and signal compounds to attract pollinating or seed dispersing animals $[26,36$, 53]. Many PSMs can be seen as nature's own pesticides and have the potential to contribute to adverse effects of chemical mixtures in aquatic ecosystems together with anthropogenic chemicals [47]. Often, the production of PSMs is specific for taxonomic groups, species, genera or families. The amounts produced are typically lower than 
those of primary metabolites [36]. Secondary metabolites are diverse in their chemical nature. Most of them belong to four major classes of compounds, namely terpenoids, phenolic compounds, alkaloids and sulfur-containing compounds [13]. Due to their biological activity, PSMs have been used for drug development including anti-inflammatory, antioxidant and antiviral agents. However, many medicinally active PSMs also show toxic side effects [10, 11, 26, 39]. For instance, bergapten, a furanocoumarin, has shown antitumor effects in a variety of cell types, but is also a potential photosensitizer that can cause severe phytophotodermatitis after either skin contact or ingestion followed by sun UV exposure $[9,43$, 51]. Some PSMs detected in the water cycle have been shown to cause severe impacts on human health such as aristolochic acids from Aristolochia clematitis causing Balkan endemic nephropathy [48] and the potent carcinogen ptaquiloside. The latter is produced by bracken fern and emitted into the water cycle particularly during rain events at toxicologically relevant concentrations [7, 35]. Recently, natural carboline alkaloids have been demonstrated to exhibit synergistic mutagenic effects with anthropogenic aromatic amines [31].

Plants produce toxic PSMs particularly under environmental stress and release these compounds to the environment through various means such as root exudates, volatilization and animal contact as part of their defence mechanism [2, 4, 10, 26]. Previous research demonstrated their pharmacological effect and toxicity by isolating them from plants $[3,42]$ and their contribution to mixture toxic risk in river water [5, 34]. In silico predictions suggest that many PSMs are persistent and mobile in the environment [14]. The authors identified priority phytotoxins characterized based on in silicopredicted values of half-life longer than 20 days, a log $\mathrm{D}_{\mathrm{OC}}$ (organic carbon-water partition coefficient) below 4.5 , rodent or aquatic toxicity and high abundance of the producing plant in Switzerland [14]. Assuming similar vegetation in Germany, these priority phytotoxins were used as a basis for target selection in the present study. PSMs may be transported to river water through leaching, rain sewers and surface run-off and might pose a risk not only to aquatic organisms, but also to human health in case of exposure, if the water is used for human consumption and recreational purposes. Recently, target and suspect screening of PSMs identified 12 compounds in Swiss small creeks from three compound classes including formononetin, an estrogenic isoflavone, the indole alkaloid gramine and several pyrrolizidine alkaloids [15]. Formononetin in concert with other isoflavones has been detected in Swiss and USA surface waters already earlier $[16,23]$. Along with other organic matters the coumarins esculetin and umbelliferone were previously reported in Suwannee River fulvic acid isolates, USA [41]. Thus, PSMs may add to the complex mixtures of anthropogenic organic micropollutants in water resources. Therefore, there are indications that some PSMs, which exhibit toxicity at environmental concentrations, may jeopardize water quality and affect aquatic ecosystems and human health in concert with anthropogenic compounds.

The objective of the present study was to perform a first river water target screening of PSM selected from a larger database for their expected mobility, persistence and toxicity, their expected abundance and their commercial availability as standards in two selected catchments with primarily natural vegetation and agricultural land use, respectively. We focused particularly on sampling during or after rain events in the vegetation season to enhance the probability of detection of PSMs leaching to the river water. Since hardly any quantitative toxicity data for PSMs is available, we compared water concentrations with TTC suggested for drinking water contaminants for which no toxicity data exist for a preliminary estimate of risks [29].

\section{Experimental section}

Study site and water sampling

The investigated catchments are located in the northwest part of the federal state of Saxony (close to the city of Leipzig) and in Saxony-Anhalt (Bode catchment), Germany. Both catchments were selected due to their land coverage with natural and/or agricultural vegetation along the river banks. The $50 \mathrm{~km}^{2}$ large floodplain forest in Leipzig reaches along the rivers Elster, Pleiße and Luppe (EPL catchment) together with some smaller tributaries. The natural old-growth deciduous forest was historically used for the extraction of coppice and clay. It is mainly characterized by Quercus robur, Fraxinus excelsior, Acer pseudoplatanus, Ulmus minor, Alnus glutinosa, Tilia cordata, Carpinus betulus, Acer platanoides and Acer campestre. In spring, the forest scrub is dominated by monocotyledonous and tuberous plants such as Allium ursinum, Anemone nemorosa, Galanthus nivalis and Leucojum vernum [22]. Thus, during their periodic growth and decay, they might leave their secondary metabolite footprints in the environmental components (e.g., soil, river). The Bode catchment is characterized by large diversity of natural and agricultural vegetation. Land use is dominated by forest (such as broad-leaved forest, coniferous forest and mixed forest) in the mountain areas and agriculture in the lowland areas. Main crops include winter wheat, triticale, winter barley, rye, rape, sugar beet and corn.

Grab water samples were collected in the vegetation growing season of the years 2018 and 2019 in spring and summer during and after rain events when leaching of 
PSMs was expected. A total of 38 rain event river samples were collected from both locations-23 samples from 6 streams situated in Leipzig and 15 samples from 15 streams in the Bode catchment (Fig. 1). In the ELP catchment, samples were taken repeatedly from the same spot at different rain event days. These samples were complemented with 18 dry weather samples (8 and 10 samples from ELP and Bode catchments, respectively) from different seasons for comparison (for more information on samples see Table S1 in supplementary information (Additional file 1). Water samples were taken with precleared glass beaker $(500 \mathrm{~mL})$ and solids were allowed to settle for about $2 \mathrm{~min}$ before transferring to sampling bottle. Aliquots of $1 \mathrm{~mL}$ were transferred to 2-mL autosampler vials for the chemical analysis. To minimize the interferences, all sampling bottles and laboratory vessels

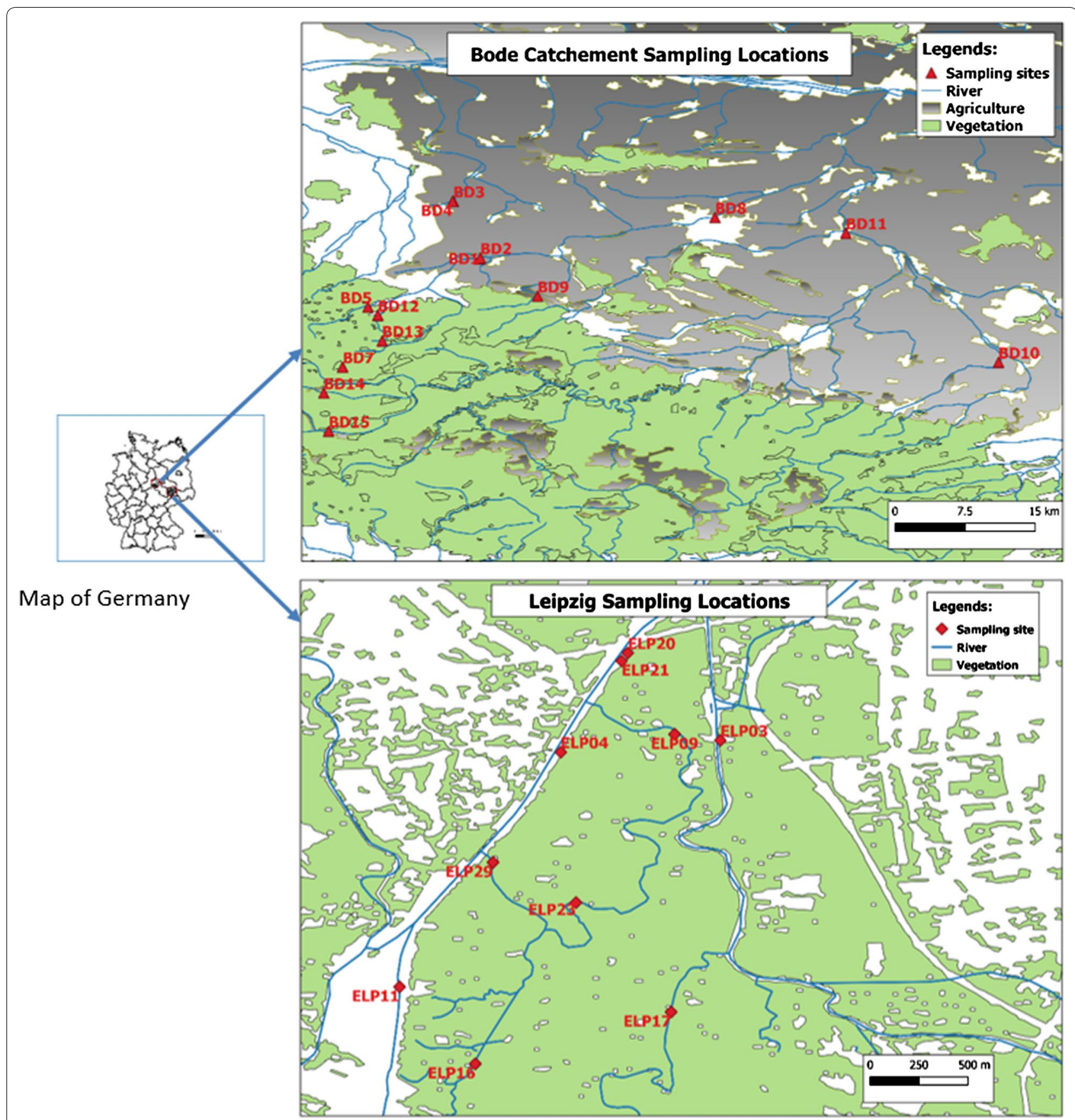

Fig. 1 Map of the sampling sites from Leipzig and Bode catchment (BD—Bode catchment, ELP—Leipzig) 
were washed and rinsed with ethyl acetate, acetone and methanol before use. Field trip and laboratory blanks were also included to control interferences during the sampling campaign and transportation. Samples were chilled with ice packs during transportation to the UFZ laboratory, and then stored at $-24{ }^{\circ} \mathrm{C}$ until analysis.

\section{Target secondary metabolite selection}

Due to limited information on PSM, in silico evaluations were performed to assess their likelihood to occur in water. Prioritization for target screening was built on previous work by Gunthardt et al., identifying plant toxins with a high probability to reach the aqueous environment due to mobility and persistence [14]. The selected metabolites represent structurally diverse natural compounds from plant species. Thus, taking these PSM as the basic population of candidate compounds, we produced a shortlist of 150 metabolites also considering commercial availability and the probability of occurrence due to the abundance of the plants identified as the origin of these metabolites (for more information see Additional file 1: Table S2). Furthermore, only metabolites containing one or more of the elements nitrogen, oxygen and sulfur, in addition to carbon and hydrogen were selected to allow for a likely ionization by an electrospray ion source [30].

\section{Chemical analysis}

Water samples containing suspended matter were filtered using a glass fiber filter (Whatman GF/A, diameter $47 \mathrm{~mm}$ ). Samples were prepared for direct injection by adding $25 \mu \mathrm{L}$ of an internal standard mixture $(40 \mathrm{ng} / \mathrm{L})$, $25 \mu \mathrm{L}$ of methanol (LC-MS grade) and $10 \mu \mathrm{L}$ of ammonium formate buffer $(2 \mathrm{M}, \mathrm{pH}=3.5)$ to each $1-\mathrm{mL}$ sample aliquot (see Additional file 1: Table S4 for more information on internal standards). For the chemical analysis, 100 $\mu \mathrm{L}$ of the sample was injected into a Thermo Ultimate 3000 LC system (consisting of a ternary pump, autosampler and column oven) coupled to a quadrupole-orbitrap instrument (Thermo QExactive Plus) equipped with a heated electrospray ionization (ESI) source.

\section{Liquid chromatography}

LC separation was performed on a Kinetex C18 EVO column $(50 \times 2.1 \mathrm{~mm}, 2.6 \mu \mathrm{m}$ particle size $)$ using a gradient elution with $0.1 \%$ of formic acid (eluent $\mathrm{A}$ ) and methanol containing $0.1 \%$ of formic acid (eluent $\mathrm{B}$ ) at a flow rate of $300 \mu \mathrm{L} / \mathrm{min}$. After $1 \mathrm{~min}$ elution with $5 \% \mathrm{~B}$, the fraction of B was linearly increased to $100 \%$ within $12 \mathrm{~min}$ and $100 \%$ B were kept for $11 \mathrm{~min}$. Subsequently, the column was rinsed with a mixture of isopropanol + acetone $50: 50 /$ eluent B/eluent A $(85 \% / 10 \% / 5 \%)$ to remove hydrophobic matrix constituents from the column. Finally, the column was re-equilibrated to initial conditions for $5.7 \mathrm{~min}$. The column was operated at $40{ }^{\circ} \mathrm{C}$.

\section{Mass spectrometry}

The heated ESI source and the transfer capillary were both operated at $300{ }^{\circ} \mathrm{C}$, with a spray voltage of $3.8 \mathrm{kV}$ (pos. mode), a sheath gas flow rate of 45 a.u. and an auxiliary gas flow rate of 1 a.u. The full-scan MS1 was recorded in an $m / z$ range from 100 to 1500 with a nominal resolving power of 140,000 (referenced to $\mathrm{m} / z 200$ ). For metabolite confirmation, data-dependent MS/MS acquisition was performed at a resolving power of 70,000 in additional runs (see Additional file 2: Table S5 for more information on MS setting). The MS was calibrated externally every 2 days using the calibration mixtures of the vendor, the mass accuracy was always below $5 \mathrm{ppm}$ for all analyses. All MS analyses were performed in ESI positive mode (ESIpos) since we expected a better ionizability of SPMs than in/with ESI negative mode.

\section{Target screening \\ Qualitative target screening}

The LC-HRMS raw data were converted to mzML format using ProteoWizard (version 2.1.0) [17]. The centroid data were subjected to MZmine (version 2.38) for peak detection followed by peak alignment and identification (target compound annotation) [20, 21, 38]. Settings for each step of the data processing are given in Additional file 2: Table S3. Further evaluation and visualization were performed using Excel 2013 (Microsoft office) and R (version 3.4.3).

Targets were identified by matching $m / z$ and retention time between water samples and standard compounds with a mass and retention time tolerance of $5 \mathrm{ppm}$ and $\pm 0.1 \mathrm{~min}$, respectively. Prior to clearing of false positives from the annotated list, the cut-off intensity was set to $10^{4}$ to exclude signals due to noise and background. For blank correction, seven blanks were analyzed together with the samples to remove noise and background contaminants. Duplicates resulting from multiple annotation were removed manually using peak resolution and intensity (for detailed steps on workflow see Additional file 2: Figure S1). For the tentatively identified target compounds, an inclusion list was developed for data-dependent acquisition (MS/MS). MS/MS experiments were conducted on authentic standard compounds and the samples to confirm the chemical structure. Diagnostic MS/MS fragments were matched with the MS/ MS of reference standards. For the target compounds with low intensity in unresolved chromatograms, parallel reaction monitoring analysis was conducted for better chromatographic peaks visualization. The XCalibur v4.0.27.10 (Thermo Fisher Scientific) software was used 
for analysis of extracted ion chromatograms (EICs) and mass spectra (MS1 and MS2).

\section{Quantification of detected metabolites}

TraceFinder 3.2 (ThermoFisher Scientific) was used for the quantification of the 12 confirmed target PSMs using extracted ion chromatograms of the full-scan data. In TraceFinder, the use of only one identifier mass (precursor ion) bares the risk of false-positive identification and quantification of contaminants. Thus, additional fragment ions were used to confirm the presence of target compounds and to eliminate errors in identification (see Additional file 2: Table S6). For some metabolites, ions used for confirmation were not clearly detectable due to low intensity. In such cases, confirmation was complemented using Xcalibur. A series of calibration standards ranging from 1 to $5000 \mathrm{ng} / \mathrm{L}$ were used. All the calibration standards were treated exactly the same way as river water samples. The target compounds were quantified using the internal standards with the nearest retention time. The method detection limit (MDLs) (Table 1) for the detected PSMs were determined following US-EPA procedure [49]. The calculated concentrations below the MDLs were excluded.

\section{Risk estimates}

Due to a lack of toxicity data for our target compounds, we based a tentative risk estimate on TTC for non-genotoxic and non-endocrine disrupting compounds of $0.1 \mu \mathrm{g} / \mathrm{L}$. We defined the ratio between measured concentration of the compounds $i\left(c_{i}\right)$ and TTC as risk quotient (RQ), and calculated mixture RQs as the sum of individual RQs (Eq. 1) assuming a mixture RQ below one as safe for exposed humans and aquatic organisms:

$$
\left(\sum \mathrm{RQ}\right)=\left(\sum \mathrm{c}_{i} \mathrm{TTC}\right)
$$

\section{Results and discussion \\ Metabolites detected in river waters}

Peak picking followed by annotation (based on MS1 fullscan) resulted in 145 target peaks with $\mathrm{m} / z$ and retention time matching to the target metabolite with a tolerance of $5 \mathrm{ppm}$ and $\pm 0.1 \mathrm{~min}$, respectively. Some target metabolites were annotated multiple times due to picking multiple peaks at a single precursor ion mass with given retention time tolerance. Removal of false positives and peak filtering using intensity and resolution reduced the target list to 106 peaks. Based on additional MS/MS fragment comparison with reference standards, we confirmed the presence of 12 target metabolites in the river waters (see Additional file 2: Figure S2-S13 for MS spectra). For the rest (94), MS/MS fragment did not match between water sample and their respective reference standard, thus discarded. They could be isobaric compounds, annotated in the given retention time window. The identified compounds belong to different classes of natural compounds including coumarins, alkaloids, isoflavone and others. In general, the identified metabolites contain one or more phenolic groups representing a class of compounds found most abundantly in vegetation [1, 39]. The names and chemical structures of the identified metabolites are given in Fig. 2.

Table 1 The concentration range ( $\min -\max , \mathrm{ng} / \mathrm{L}$ ) of identified plant metabolites in river water

\begin{tabular}{|c|c|c|c|c|c|c|c|c|c|}
\hline \multirow[t]{2}{*}{ Plant secondary metabolite } & \multirow[t]{2}{*}{ Chemical formula } & \multirow[t]{2}{*}{ CAS no. } & \multirow[t]{2}{*}{$m / z\left(M+H^{+}\right)$} & \multirow[t]{2}{*}{$\begin{array}{l}\text { Retention } \\
\text { time (min) }\end{array}$} & \multirow[t]{2}{*}{ MDL (ng/L) } & \multicolumn{2}{|c|}{$\begin{array}{l}\text { Concentration range } \\
\text { (min-max, ng/L) }\end{array}$} & \multicolumn{2}{|c|}{$\begin{array}{l}\text { Frequency } \\
\text { of detection }\end{array}$} \\
\hline & & & & & & Leipzig & Bode & Leipzig & Bode \\
\hline Coumarin & $\mathrm{C}_{9} \mathrm{H}_{6} \mathrm{O}_{2}$ & $91-64-5$ & 147.0441 & 7.3 & 11 & 12 & 43 & 1 & 1 \\
\hline Esculetin & $\mathrm{C}_{9} \mathrm{H}_{6} \mathrm{O}_{4}$ & $305-01-1$ & 179.0336 & 4.2 & 50 & $116-1658$ & $104-157$ & 2 & 3 \\
\hline Fraxidin & $\mathrm{C}_{11} \mathrm{H}_{10} \mathrm{O}_{5}$ & $525-21-3$ & 223.0600 & 7.8 & 4 & $56-1145$ & 19-155 & 9 & 8 \\
\hline Scopoletin & $\mathrm{C}_{10} \mathrm{H}_{8} \mathrm{O}_{4}$ & $92-61-5$ & 193.0496 & 7.1 & 2 & $9-47$ & $7-49$ & 9 & 9 \\
\hline Bergapten & $\mathrm{C}_{12} \mathrm{H}_{8} \mathrm{O}_{4}$ & $484-20-8$ & 217.0495 & 10.1 & 4 & 510 & 541 & 1 & 1 \\
\hline Psoralen & $\mathrm{C}_{11} \mathrm{H}_{6} \mathrm{O}_{3}$ & $66-97-7$ & 187.0388 & 9.1 & 3 & ND & $141-224$ & 0 & 2 \\
\hline Lycorine & $\mathrm{C}_{16} \mathrm{H}_{17} \mathrm{NO}_{4}$ & $476-28-8$ & 288.1225 & 1.0 & 3 & $1015-2331$ & 11 & 2 & 1 \\
\hline Narciclasine & $\mathrm{C}_{14} \mathrm{H}_{13} \mathrm{NO}_{7}$ & 29477-83-6 & 308.0765 & 5.7 & 150 & $507-3353$ & ND & 2 & - \\
\hline Nicotine & $\mathrm{C}_{10} \mathrm{H}_{14} \mathrm{~N}_{2}$ & $54-11-5$ & 163.1228 & 0.9 & 1.6 & $2-6$ & $4-35$ & 2 & 2 \\
\hline Piperine & $\mathrm{C}_{17} \mathrm{H}_{19} \mathrm{NO}_{3}$ & $94-62-2$ & 286.1434 & 11.9 & 0.9 & $1-338$ & $4-294$ & 4 & 2 \\
\hline Formononetin & $\mathrm{C}_{16} \mathrm{H}_{12} \mathrm{O}_{4}$ & $485-72-3$ & 269.0804 & 10.8 & 3 & $8-35$ & 123 & 5 & 1 \\
\hline Coniferyl aldehyde & $\mathrm{C}_{10} \mathrm{H}_{10} \mathrm{O}_{3}$ & $458-36-6$ & 179.0701 & 7.6 & 8 & $13-46$ & ND & 2 & - \\
\hline
\end{tabular}

ND not detected 
<smiles>COc1c2ccoc2cc2oc(=O)ccc12</smiles><smiles>COc1cc2ccc(=O)oc2c(O)c1OC</smiles>

Fraxidin<smiles>OC1C=C2CCN3Cc4cc5c(cc4C(C1O)C23)OCO5</smiles><smiles>O=c1ccc2ccccc2o1</smiles>

Coumarin<smiles>O=c1ccc2cc3ccoc3cc2o1</smiles>

Psoralen<smiles>O=c1ccc2cc(O)c(O)cc2o1</smiles>

Esculetin<smiles>COc1cc2ccc(=O)oc2cc1O</smiles><smiles>O=C1NC2C(=CC(O)C(O)C2O)c2cc3c(c(O)c21)OCO3</smiles>

Piperine<smiles>COc1ccc(-c2coc3cc(O)ccc3c2=O)cc1</smiles>

Formononetin

Fig. 2 Plant secondary metabolites identified in river waters

\section{Distribution of measured metabolites in river waters}

In 18 out of 38 rain event samples PSMs were detected (9 samples from each catchment-Leipzig and Bode), while in none of the dry weather control samples any of the target PSMs were found. It is apparent that, in about $50 \%$ (20) rain event samples the target compounds were not detected. In the Bode catchment, larger numbers of metabolites were detected in rivers impacted by agricultural than natural vegetation (Fig. 1 and Additional file 2: Table S7).

Among the identified 12 metabolites, 11 were detected in samples from the ELP catchment and 10 were found in the Bode catchment. In both catchments, the coumarin derivatives scopoletin and fraxidin were detected with the highest frequency with 9 samples from each catchments (Fig. 3a and b). Esculetin, another coumarin derivative was the third most frequently detected PSM in the Bode catchment with $20 \%$ while it was detected in $9 \%$ of the samples from the ELP catchment. The high detection frequency of fraxidin and esculetin is in good agreement with its formation by Fraxinus excelsior, a frequent tree in central European floodplains including the ones under investigation here. Scopoletin is produced by Scopolia species, but also the very frequently occurring stinging nettle Urtica dioica. However, all three compounds are present in a wide range of plants, which might contribute to emissions [52]. The isoflavone formononetin is the third most frequently occurring PSM in the ELP catchment with $22 \%$, while it was found in $7 \%$ of the Bode catchment samples. Other compounds were detected only in specific samples from a specific season such as lycorine and narciclasine occurring in Amaryllidaceae, which show a high abundance within short 

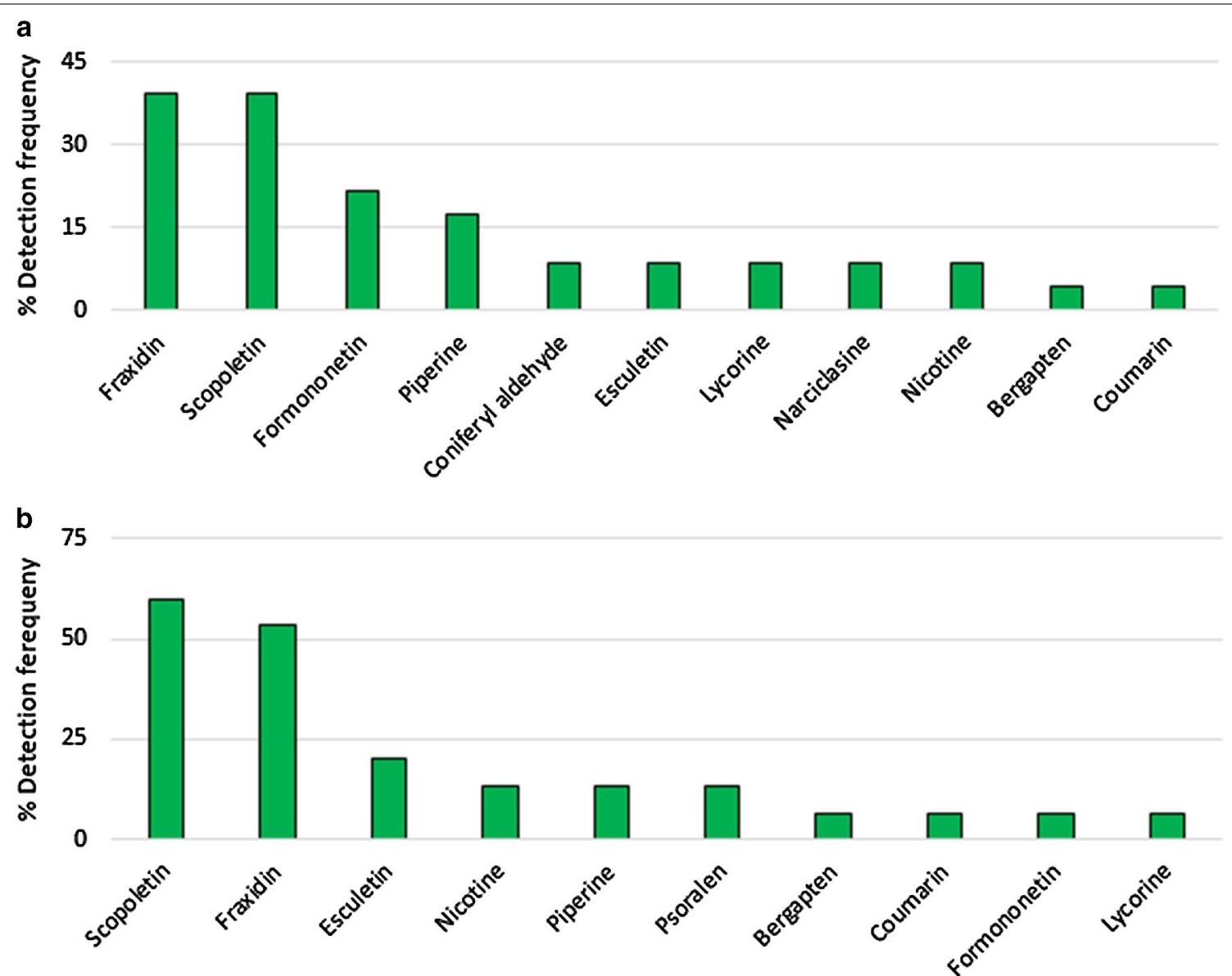

Fig. 3 Detection frequency of metabolites in rain event river water samples from ELP (a) and Bode catchment (b)

growth periods such as Galanthus species in early spring. Although coniferyl aldehyde is a lignin component of many plants, it could be detected only in the EPL catchment and the coumarin psoralen only in Bode catchment. Natural compounds stemming likely from human consumption such as the piperidine alkaloid piperine as a component of pepper and nicotine from tobacco could be detected in both catchments.

\section{Quantification of PSMs in river water}

The target PSMs were detected in a concentration range of 1-3400 ng/L (Table 1). The concentrations of identified metabolites in individual samples are given in Additional file 2: Table S7. The highest concentrations were detected for lycorine and narciclasine with maximum concentrations of 2 and $3 \mu \mathrm{g} / \mathrm{L}$ during the times of high abundance of Galanthus sp. (snowdrop) and Leucojum vernum (spring snowflake). The concentrations of these phytotoxins strongly exceed the TTC of $0.1 \mu \mathrm{g} / \mathrm{L}$ for nongenotoxic and non-endocrine disrupting compounds and would be of concern, if these water resources would be used for drinking water production. Both compounds are highly bioactive and toxic causing among others nausea and emesis in human and animals $[24,25]$. Lycorine demonstrated acetylcholinesterase inhibition effects at $\mathrm{IC}_{50}$ of $213 \mu \mathrm{g} / \mathrm{L}$ [18, 32], while other authors reported above 1000 [6]. So, apart from its toxicity, lycorine also has more positive effects, as many SPMs, such as antibacterial, anti-viral, anti-malarial, anti-allergy effects, inhibits protein and DNA synthesis and has cardiovascular protection and antitumor effects [19].

The second group of PSMs exceeding the TTC of $0.1 \mu \mathrm{g} / \mathrm{L}$ is the coumarin derivatives with fraxidin and esculetin concentrations of 19 to $1145 \mathrm{ng} / \mathrm{L}$ and 116 to $1658 \mathrm{ng} / \mathrm{L}$, respectively, while coumarin and scopoletin remained below $50 \mathrm{ng} / \mathrm{L}$ (Table 1). A maximum concentration of $300 \mu \mathrm{g} / \mathrm{L}$ esculetin was previously reported in Suwannee River fulvic acid isolates, USA [41]. In general, samples from the ELP catchment showed higher concentrations of coumarins than those from the Bode catchment. All four compounds have been isolated from Fraxinus excelsior [22, 40, 50, 52], a characteristic tree 
along the rivers in both catchments. Coumarins comprise a very large class of substances, found in several higher plants and constitute fused benzene and pyrone rings $[33,45,52]$. Simple coumarins have been found to be biologically active with anti-stress, anti-fatigue, antigastric ulcer, anti-depressive, immuno-enhancing and anti-inflammatory effects [52, 54]. Scopoletin, isolated from Scopolia carniolica (Solanaceae), was shown to inhibit acetylcholinesterase at $\mathrm{IC}_{50}$ of $169 \mu \mathrm{g} / \mathrm{L}$ in vitro assay [18].

Two furanocoumarins, bergapten and psoralen, have been detected in only two samples, each, from both catchments but in all cases above the TTC with 510 and $541 \mathrm{ng} / \mathrm{L}$ for bergapten and 141 and $224 \mathrm{ng} / \mathrm{L}$ for psoralen. They are synthesized by several plants, especially by those of the Apiaceace family [43]. They are generally known for their strong photosensitizing activity when applied topically or accidentally get in contact to the skin. The exposure to furanocoumarins combined with long UV radiation causes cytotoxic reactions (e.g., erythema) and genotoxic responses by binding to nucleobases in DNA $[43,51]$.

The flavonoid, formononetin was detected in five samples from the ELP catchment at a concentration range of 8-35 ng/L and in one sample from Bode catchment with $123 \mathrm{ng} / \mathrm{L}$ again exceeding the TTC. The latter was taken from an agricultural area $[16,23]$. The PSM occurs in many leguminous plants such as clover (Trifolium), an abundant species in fertile meadows and pastures but also beans such as green beans, lima beans and soy [1, 33, 39]. Formononetin has been shown to display estrogenic properties with an $\mathrm{IC}_{50}$ of $104 \mu \mathrm{g} / \mathrm{L}$ in vitro [28] and induce angiogenesis activities [27].

In both catchments, also the PSMs nicotine and piperine have been found in concentrations of 2 to $35 \mathrm{ng} / \mathrm{L}$ and 1-338 ng/L again with two samples exceeding the TTC. The input of both metabolites to the river water is very likely due to human activities, while no plants containing these compounds in the catchments are known. Both PSMs are widely consumed by humans and related to tobacco smoking and food flavoring, respectively. Nicotine is highly addictive and acts as a receptor agonist at most nicotinic acetylcholine receptors (nAChRs) [12]. Piperine is a major component of Piper species (e.g., Piper nigrum, Piper longum, Piper officinarum and Piper retrofractum), which are globally marketed as flavoring agent and cooking spice with a long history of human health benefits and a wide consumption $[44,46]$. Piperine has been found to have numerous medicinal applications such as antioxidant, antiplatelet, anti-inflammatory, antihypertensive, hepatoprotective, antithyroid, antitumor, antiasthmatic activity and has also been used as fertility enhancer [8]. Apart from its numerous benefits, it may also have adverse effects including hemorrhagic necrosis and edema in gastrointestinal tract, urinary bladder and adrenal glands observed in animal tests with rats [37]. Zwart et al. detected piperine in waste water treatment plant effluent and classified it as one of the most potent nonsteroidal estrogens at $\mathrm{EC}_{50}$ of $300 \mathrm{ng} / \mathrm{L}$ in vitro [55], which is in the same order of magnitude as the concentrations obtained in the present study.

\section{Co-occurrence of PSMs}

Similar to anthropogenic compounds, also PSMs occur in mixtures. In all of the samples, where we detected our target PSMs, we found at least two of them, at two sites (11\% (2) of positive samples), we detected even six co-occurring PSMs (Fig. 4a). The compounds fraxidin and scopoletin were common to all samples, with only one exception in the Bode catchment. Based on TTC of

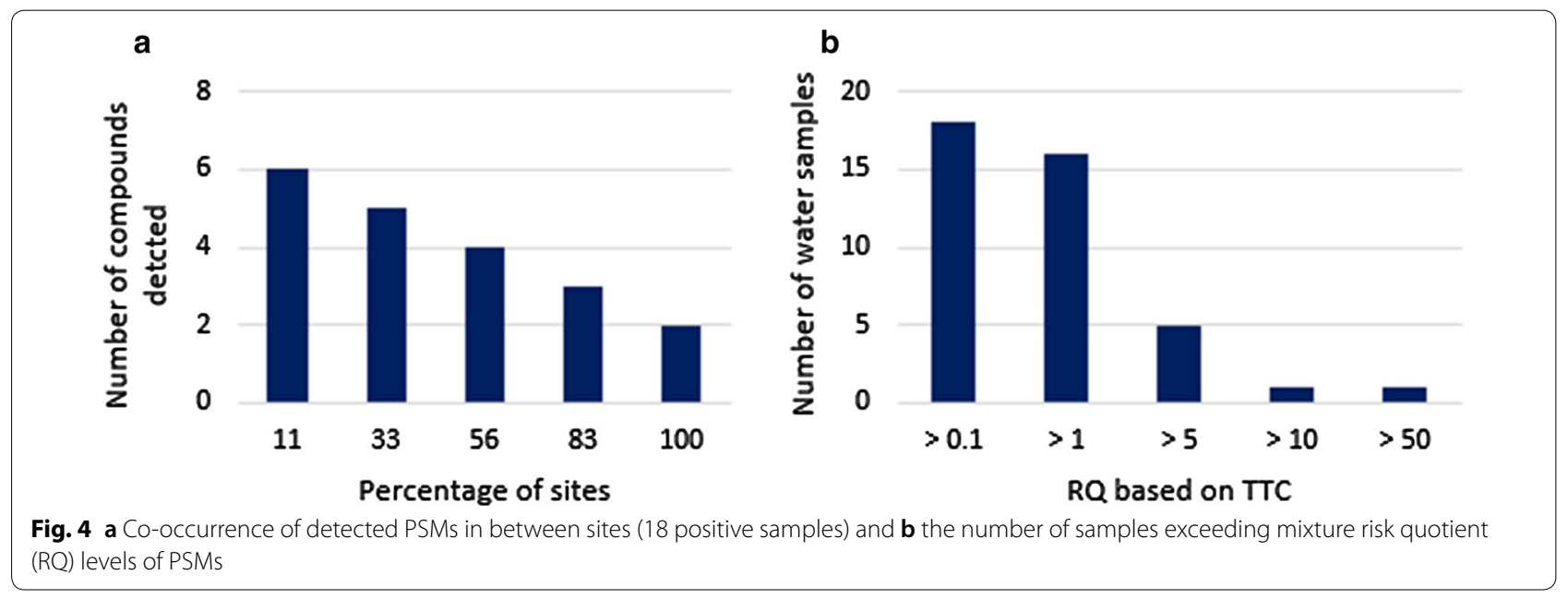


$0.1 \mu \mathrm{g} / \mathrm{L}$, mixture risks exceeded a RQ of 1 at 16 out of 18 sites, at 5 sites mixture RQ was above 5 . At one site each, even RQs of 10 and 50 were exceeded (Fig. 4b). This may indicate that toxic risks by frequently occurring PSMs may not be negligible and should be included in risk assessment of chemical mixtures in water resources.

\section{Conclusion}

By target screening of 150 prioritized PSMs in river water from two small catchments in Germany, we were able to detect 12 compounds of different classes (e.g., coumarins, flavonoids, alkaloids and others), some of them occurring frequently. In many cases, concentrations of these compounds, which are known to exhibit substantial biological activity and possibly toxic effect, exceeded the concentrations of many anthropogenic chemicals in surface waters and TTC for drinking water individually and as mixture in almost all samples, in few cases by more than one order of magnitude. This finding clearly indicates that PSMs and other natural compounds should be included into monitoring and risk assessment and should be considered in the context of drinking water abstraction. A potential risk particularly during rain events promoting the leaching of PSMs to surface waters and massive occurrence of toxic plants in specific seasons may not be excluded. Large-scale seasonal target and suspect screening of PSMs together with toxicity testing of frequently occurring and high-concentration compounds is required to estimate the contribution of PSMs to overall water pollution and to identify seasons and situations potentially posing a risk to drinking water production. Toxic risks to aquatic ecosystems might be relevant, particularly in areas where vegetation undergoes drastic changes, for example by massive occurrence of toxic invasive species or by substantial changes in land use. Thus, we recommend to consider PSMs in monitoring and risk assessment of water resources. This is currently hampered by a lack of effect data including toxicity to aquatic organisms, endocrine disruption and genotoxicity and demands for biotesting of these compounds.

\section{Supplementary information}

Supplementary information accompanies this paper at https://doi. org/10.1186/s12302-020-00399-2.

Additional file 1. Samples, target compounds and internal standards.

Additional file 2. Data evaluation and results

\section{Abbreviations}

LC-HRMS: Liquid chromatography coupled to high-resolution mass spectrometry; PSMs: Plant secondary metabolites; ELP: Elster, Luppe and Pleiße catchment; BD: Bode catchment; TTC: Threshold for toxicological concern; MS: Mass spectrometry; RQ: Risk quotient; MDLs: Method detection limit.

\section{Acknowledgements}

The authors would like to thank the European Commission for funding the NaToxAq project (Grant agreement ID: 722493); analyses were run on the high-throughput platform CITEPro (Chemicals in the Environment Profiler) funded by the Helmholtz Association. A free academic licence of JChem for office (Excel) used for the structure-based property and Marvin/JChem 17.21.0, 2019 ChemAxon (https://www.chemaxon.com). QGIS 3.4.15 was used to map the sampling sites.

\section{Authors' contributions}

MYN: conceptualization, investigation, experimental analysis, target compound selection, data evaluation and visualization, writing (original draft). MK: conceptualization, investigation, writing - review and editing; WB: conceptualization, supervision, writing—review and editing. CDS, BFG and TDB: in silico prediction and selection of target compounds, review and editing. All authors read and approved the final manuscript.

\section{Funding}

Open Access funding enabled and organized by Projekt DEAL. This study has received funding from the European Union's Horizon 2020 research and innovation programme under the Marie Sklodowska-Curie grant agreement No. 722493.

\section{Availability of data and materials}

The datasets obtained and analyzed in the current study are available from the corresponding author on reasonable request.

Ethics approval and consent to participate

Not applicable.

\section{Consent for publication}

Not applicable.

\section{Competing interest}

The authors declare that they have no competing interests.

\section{Author details}

${ }^{1}$ Department of Effect-Directed Analysis, Helmholtz Centre for Environmental Research-UFZ, Permoserstraße 15, 04318 Leipzig, Germany. ${ }^{2}$ Department of Evolutionary Ecology and Environmental Toxicology, Faculty of Biological Sciences, Goethe University Frankfurt, Max-von-Laue Str. 13, 60438 Frankfurt (Main), Germany. ${ }^{3}$ Agroscope, Environmental Analytics, Reckenholzstrasse 191, 8046 Zurich, Switzerland. ${ }^{4}$ Department of Environmental Systems Science, ETH Zürich, Universitätsstraße 16, 8092 Zurich, Switzerland.

Received: 16 June 2020 Accepted: 14 September 2020

Published online: 23 October 2020

\section{References}

1. Afendi FM, Okada T, Yamazaki M, Hirai-Morita A, Nakamura Y, Nakamura K, Ikeda S, Takahashi H, Altaf-UI-Amin M, Darusman LK, Saito K, Kanaya S (2011) KNApSAcK family databases: integrated metabolite-plant species databases for multifaceted plant research. Plant Cell Physiol. https://doi. org/10.1093/pcp/pcr165

2. Al-Shatti AH, Redha A, Suleman P, Al-Hasan R (2014) The allelopathic potential of Conocarpus lancifolius (Engl.) leaves on dicot (Vigna sinensis L.), Monocot (Zea mays L.) and soil-Borne pathogenic fungi. Am J Plant Sci 5(19):2889-2903. https://doi.org/10.4236/ajps.2014.519304

3. Altemimi A, Lakhssassi N, Baharlouei A, Watson DG, Lightfoot DA (2017) Phytochemicals: extraction, isolation, and identification of bioactive compounds from plant extracts. Plants 6(4):1-23. https://doi.org/10.3390/ plants6040042

4. Aulakh MS, Wassmann R, Bueno C, Kreuzwieser J, Rennenberg $\mathrm{H}$ (2001) Characterization of root exudates at different growth stages of ten rice (Oryza sativa L.) cultivars. Plant Biol 3(2):139-148. https://doi. org/10.1055/s-2001-12905 
5. Bucheli TD (2014) Phytotoxins: environmental micropollutants of concern? Environ Sci Technol 48(22):13027-13033. https://doi.org/10.1021/ es504342w

6. Cahlikova L, Hrabinova M, Kulhankova A, Benesova N, Chlebek J, Jun D, Novak Z, Macakova K, Kunes J, Kuca K, Opletal L (2013) Alkaloids from Chlidanthus fragrans and their acetylcholinesterase, butyrylcholinesterase and prolyl oligopeptidase activities. Nat Prod Commun 8(11):1541-1544

7. Clauson-Kaas F, Ramwell C, Hansen HCB, Strobel BW (2016) Ptaquiloside from bracken in stream water at base flow and during storm events. Water Res 106:155-162. https://doi.org/10.1016/j.watres.2016.09.049

8. Derosa G, Maffioli P, Sahebkar A (2016) Piperine and its role in chronic diseases. Adv Exp Med Biol 928:173-184. https://doi.org/10.1007/978-3319-41334-1_8

9. Dugrand-Judek A, Olry A, Hehn A, Costantino G, Ollitrault P, Froelicher Y, Bourgaud $F$ (2015) The distribution of coumarins and furanocoumarins in citrus species closely matches citrus phylogeny and reflects the organization of biosynthetic pathways. PLoS ONE 10(11):e0142757. https://doi. org/10.1371/journal.pone.0142757

10. Edreva A, Velikova V, Tsonev T, Dagnon S, Gürel AL, Aktaş L (2007) Stressprotective role of secondary metabolites: diversity of functions and mechanisms. Gen Appl Plant Physiol 34(1-2):67-78

11. Furst R (2016) Narciclasine —an amaryllidaceae alkaloid with potent antitumor and anti-inflammatory properties. Planta Med 82(16):1389-1394. https://doi.org/10.1055/s-0042-115034

12. Godin JR, Roy P, Quadri M, Bagdas D, Toma W, Narendrula-Kotha R, Kishta OA, Damaj MI, Horenstein NA, Papke RL, Simard AR (2019) A silent agonist of alpha7 nicotinic acetylcholine receptors modulates inflammation ex vivo and attenuates EAE. Brain Behav Immun. https://doi. org/10.1016/j.bbi.2019.12.014

13. Guerriero G, Berni R, Muñoz-Sanchez JA, Apone F, Abdel-Salam EM, Qahtan AA, Alatar AA, Cantini C, Cai G, Hausman J-F, Siddiqui KS, Hernández-Sotomayor SMT, Faisal M (2018) Production of plant secondary metabolites: examples, tips and suggestions for biotechnologists. Genes 9(6):309. https://doi.org/10.3390/genes9060309

14. Gunthardt BF, Hollender J, Hungerbuhler K, Scheringer M, Bucheli TD (2018) Comprehensive toxic plants-phytotoxins database and its application in assessing aquatic micropollution potential. J Agric Food Chem 66(29):7577-7588. https://doi.org/10.1021/acs.jafc.8b01639

15. Gunthardt BF, Schonsee CD, Hollender J, Hungerbuhler $K$, Scheringer $M$ Bucheli TD (2020) "Is there anybody else out there?"-First insights from a suspect screening for phytotoxins in surface water. Chimia 74(3):129-135. https://doi.org/10.2533/chimia.2020.129

16. Hoerger CC, Wettstein FE, Hungerbuhler K, Bucheli TD (2009) Occurrence and origin of estrogenic isoflavones in swiss river waters. Environ Sci Technol 43(16):6151-6157. https://doi.org/10.1021/es901034u

17. Holman JD, Tabb DL, Mallick P (2014) Employing ProteoWizard to convert raw mass spectrometry data. Curr Protoc Bioinform 46(1):13.24.1113.24.19. https://doi.org/10.1002/0471250953.bi1324s46

18. Hostettmann K, Borloz A, Urbain A, Marston A (2006) Natural product inhibitors of acetylcholinesterase. Curr Org Chem 10(8):825-847. https:// doi.org/10.2174/138527206776894410

19. Jahn S, Seiwert B, Kretzing S, Abraham G, Regenthal R, Karst U (2012) Metabolic studies of the Amaryllidaceous alkaloids galantamine and lycorine based on electrochemical simulation in addition to in vivo and in vitro models. Anal Chim Acta 756:60-72. https://doi.org/10.1016/j. aca.2012.10.042

20. Katajamaa M, Miettinen J, Oresic M (2006) MZmine: toolbox for processing and visualization of mass spectrometry based molecular profile data. Bioinformatics 22(5):634-636. https://doi.org/10.1093/bioinformatics/ btk039

21. Katajamaa M, Oresic M (2005) Processing methods for differential analysis of LC/MS profile data. BMC Bioinform 6:179. https://doi. org/10.1186/1471-2105-6-179

22. Klimo E, Hager H (2001) The floodplain forests in Europe: current situations and perspectives. Brill

23. Kolpin DW, Hoerger CC, Meyer MT, Wettstein FE, Hubbard LE, Bucheli TD (2010) Phytoestrogens and mycotoxins in lowa streams: an examination of underinvestigated compounds in agricultural basins. J Environ Qual 39(6):2089-2099. https://doi.org/10.2134/jeq2010.0121
24. Kornienko A, Evidente A (2008) Chemistry, biology, and medicinal potential of narciclasine and its congeners. Chem Rev 108(6):1982-2014. https ://doi.org/10.1021/cr078198u

25. Kretzing S, Abraham G, Seiwert B, Ungemach FR, Krugel U, Teichert J, Regenthal $R$ (2011) In vivo assessment of antiemetic drugs and mechanism of lycorine-induced nausea and emesis. Arch Toxicol 85(12):15651573. https://doi.org/10.1007/s00204-011-0719-9

26. Lavecchia T, Rea G, Antonacci A, Giardi MT (2013) Healthy and adverse effects of plant-derived functional metabolites: the need of revealing their content and bioactivity in a complex food matrix. Crit Rev Food Sci Nutr 53(2):198-213. https://doi.org/10.1080/10408398.2010.520829

27. Li S, Dang Y, Zhou X, Huang B, Huang X, Zhang Z, Kwan YW, Chan SW, Leung GPH, Lee SMY, Hoi MPM (2015) Formononetin promotes angiogenesis through the estrogen receptor alpha-enhanced ROCK pathway. Sci Rep 5:16815. https://doi.org/10.1038/srep16815

28. Liu J, Burdette JE, Xu H, Gu C, van Breemen RB, Bhat KPL, Booth N, Constantinou Al, Pezzuto JM, Fong HHS, Farnsworth NR, Bolton JL (2001) Evaluation of estrogenic activity of plant extracts for the potential treatment of menopausal symptoms. J Agric Food Chem 49(5):2472-2479. https://doi.org/10.1021/jfo014157

29. Mons MN, Heringa MB, van Genderen J, Puijker LM, Brand W, van Leeuwen CJ, Stoks P, van der Hoek JP, van der Kooij D (2013) Use of the Threshold of Toxicological Concern (TTC) approach for deriving target values for drinking water contaminants. Water Res 47(4):1666-1678. https ://doi.org/10.1016/j.watres.2012.12.025

30. Moschet C, Piazzoli A, Singer H, Hollender J (2013) Alleviating the reference standard dilemma using a systematic exact mass suspect screening approach with liquid chromatography-high resolution mass spectrometry. Anal Chem 85(21):10312-10320. https://doi.org/10.1021/ac4021598

31. Muz M, Krauss M, Kutsarova S, Schulze T, BrackW (2017) Mutagenicity in surface waters: synergistic effects of carboline alkaloids and aromatic amines. Environ Sci Technol 51(3):1830-1839. https://doi.org/10.1021/acs. est.6b05468

32. Nair JJ, van Staden J (2012) Acetylcholinesterase inhibition within the lycorine series of Amaryllidaceae alkaloids. Nat Prod Commun 7(7):959-962

33. Nakamura K, Shimura N, Otabe Y, Hirai-Morita A, Nakamura Y, Ono N, UIAmin MA, Kanaya S (2013) KNApSAcK-3D: a three-dimensional structure database of plant metabolites. Plant Cell Physiol 54(2):e4. https://doi. org/10.1093/pcp/pcs 186

34. O'Driscoll C, Ramwell C, Harhen B, Morrison L, Clauson-Kaas F, Hansen HC, Campbell G, Sheahan J, Misstear B, Xiao L (2016) Ptaquiloside in Irish bracken ferns and receiving waters, with implications for land managers. Molecules 21(5):543. https://doi.org/10.3390/molecules21050543

35. Ojika M, Wakamatsu K, Niwa H, Yamada K (1987) Ptaquiloside, a potent carcinogen isolated from bracken fern pteridiumaquilinum var. latiusculum: structure elucidation based on chemical and spectral evidence, and reactions with amino acids, nucleosides, and nucleotides. Tetrahedron 43(22):5261-5274. https://doi.org/10.1016/s0040-4020(01)87702-4

36. Pichersky E, Gang DR (2000) Genetics and biochemistry of secondary metabolites in plants: an evolutionary perspective. Trends Plant Sci 5(10):439-445. https://doi.org/10.1016/s1360-1385(00)01741-6

37. Piyachaturawat P, Glinsukon T, Toskulkao C (1983) Acute and subacute toxicity of piperine in mice, rats and hamsters. Toxicol Lett 16(3-4):351359. https://doi.org/10.1016/0378-4274(83)90198-4

38. Pluskal T, Castillo S, Villar-Briones A, Orešič M (2010) MZmine 2: modular framework for processing, visualizing, and analyzing mass spectrometrybased molecular profile data. BMC Bioinform 11(1):395. https://doi. org/10.1186/1471-2105-11-395

39. Puri B, Hall A, Baxter H, Harborne JB, Moss GP (1998) Phytochemical dictionary: a handbook of bioactive compounds from plants, 2nd edn. CRC Press, London

40. Qazi SS, Lombardo DA, Abou-Zaid MM (2018) A Metabolomic and HPLC-MS/MS analysis of the foliar phenolics, flavonoids and coumarins of the Fraxinus species resistant and susceptible to emerald ash borer. Molecules 23(11):2734. https://doi.org/10.3390/molecules23112734

41. Remucal CK, Cory RM, Sander M, McNeill K (2012) Low molecular weight components in an aquatic humic substance as characterized by membrane dialysis and orbitrap mass spectrometry. Environ Sci Technol 46(17):9350-9359. https://doi.org/10.1021/es302468q 
42. Sasidharan S, Chen Y, Saravanan D, Sundram KM, Yoga Latha L (2011) Extraction, isolation and characterization of bioactive compounds from plants' extracts. Afr J Tradit Complement Altern Med 8(1):1-10

43. Schlatter J, Zimmerli B, Dick R, Panizzon R, Schlatter C (1991) Dietary intake and risk assessment of phototoxic furocoumarins in humans. Food Chem Toxicol 29(8):523-530. https://doi.org/10.1016/02786915(91)90044-8

44. Schnabel A, Cotinguiba F, Athmer B, Yang C, Westermann B, Schaks A, Porzel A, Brandt W, Schumacher F, Vogt T (2020) A piperic acid CoA ligase produces a putative precursor of piperine, the pungent principle from black pepper fruits. Plant J 102(3):569-581. https://doi.org/10.1111/ tpj.14652

45. Shinbo Y, Nakamura Y, Altaf-Ul-Amin M, Asahi H, Kurokawa K, Arita M, Saito K, Ohta D, Shibata D, Kanaya S (2006) KNApSAcK: A comprehensive species-metabolite relationship database. In: Saito K, Dixon RA, Willmitzer L (eds) Plant metabolomics. Springer, Berlin, pp 165-181. https://doi. org/10.1007/3-540-29782-0_13

46. Shoba G, Joy D, Joseph T, Majeed M, Rajendran R, Srinivas PSSR (1998) Influence of piperine on the pharmacokinetics of curcumin in animals and human volunteers. Planta Med 64(04):353-356. https://doi. org/10.1055/s-2006-957450

47. Singh HP, Batish DR, Kohli RK (2003) Allelopathic interactions and allelochemicals: new possibilities for sustainable weed management. Crit Rev Plant Sci 22(3-4):239-311. https://doi.org/10.1080/713610858

48. Tung KK, Chan CK, Zhao Y, Chan KJ, Liu G, Pavlović NM, Chan W (2020) Occurrence and environmental stability of aristolochic acids in groundwater collected from Serbia: links to human exposure and Balkan endemic nephropathy. Environ Sci Technol 54(3):1554-1561. https://doi. org/10.1021/acs.est.9b05337

49. US-EPA (2011) 40 CFR Part 136, Appendix B to Part 136-definition and procedure for the determination of the method detection limit-revision 1.11. 40
50. Venugopala KN, Rashmi V, Odhav B (2013) Review on natural coumarin lead compounds for their pharmacological activity. Biomed Res Int 2013:963248. https://doi.org/10.1155/2013/963248

51. Walter JF, Gange RW, Mendelson IR (1982) Psoralen-containing sunscreen induces phototoxicity and epidermal ornithine decarboxylase activity. J Am Acad Dermatol 6(6):1022-1027. https://doi.org/10.1016/s0190 -9622(82)70086-6

52. Whang WK, Park HS, Ham I, Oh M, Namkoong H, Kim HK, Hwang DW, Hur SY, Kim TE, Park YG, Kim JR, Kim JW (2005) Natural compounds, fraxin and chemicals structurally related to fraxin protect cells from oxidative stress. Exp Mol Med 37(5):436-446. https://doi.org/10.1038/emm.2005.54

53. Wink M (2003) Evolution of secondary metabolites from an ecological and molecular phylogenetic perspective. Phytochemistry 64(1):3-19. https://doi.org/10.1016/s0031-9422(03)00300-5

54. Witaicenis A, Seito LN, Di Stasi LC (2010) Intestinal anti-inflammatory activity of esculetin and 4-methylesculetin in the trinitrobenzenesulphonic acid model of rat colitis. Chem Biol Interact 186(2):211-218. https ://doi.org/10.1016/j.cbi.2010.03.045

55. Zwart N, Nio SL, Houtman CJ, de Boer J, Kool J, Hamers T, Lamoree MH (2018) High-throughput effect-directed analysis using downscaled in vitro reporter gene assays to identify endocrine disruptors in surface water. Environ Sci Technol 52(7):4367-4377. https://doi.org/10.1021/acs. est.7b06604

\section{Publisher's Note}

Springer Nature remains neutral with regard to jurisdictional claims in published maps and institutional affiliations.

\section{Submit your manuscript to a SpringerOpen ${ }^{\circ}$ journal and benefit from:}

- Convenient online submission

- Rigorous peer review

- Open access: articles freely available online

- High visibility within the field

- Retaining the copyright to your article

Submit your next manuscript at $\boldsymbol{\nabla}$ springeropen.com 